\title{
Comparing the Contribution of Visible-Light Irradiation, Gold Nanoparticles, and Titania Supports in Photocatalytic Nitroaromatic Coupling and Aromatic Alcohol Oxidation
}

\author{
Jian Zhao, Xuebin Ke, Hongwei Liu, Yiming Huang, Chao Chen, Arixin Bo, \\ Xianliang Sheng, and Huaiyong Zhu*
}

School of Chemistry, Physics, and Mechanic Engineering Queensland University of Technology GPO Box 2434, Brisbane, QLD 4001, Australia; E-mail: hyzhu@qut.edu.au

\begin{abstract}
Under visible-light irradiation, gold nanoparticles (Au NPs) supported by titania $\left(\mathrm{TiO}_{2}\right)$ nanofibers show excellent activity and high selectivity for both reduc- tive coupling of nitroaromatics to corresponding azobenzene or azoxylbenzene and selective oxidation of aromatic alcohols to corresponding aldehydes. The Au NPs act as active centers mainly due to their localized surface plasmon resonance (LSPR) effect. They can effectively couple the photonic energy and thermal energy to enhance reaction efficiency. Visible-light irradiation has more influence on the reduction than on the oxidation, lowering the activation energy by $24.7 \mathrm{~kJ} \mathrm{~mol}^{-1}$ and increasing the conversion rate by $88 \%$ for the reductive coupling, compared to merely $8.7 \mathrm{~kJ} \mathrm{~mol}^{-1}$ and $46 \%$ for the oxidation. Furthermore, it is found that the conversion of nitroaromatics significantly depends on the particle size and specific surface area of supported $\mathrm{Au}$ NPs; and the catalyst on $\mathrm{TiO}_{2}(\mathrm{~B})$ support outperforms that on anatase phase with preferable ability to activate oxygen. In contrast, for the selective oxidation, the effect of surface area is less prominent and Au NPs on anatase exhibit higher photo-catalytic activity than other $\mathrm{TiO}_{2}$ phases. The catalysts can be recovered efficiently because the Au NPs stably attach to $\mathrm{TiO}_{2}$ supports by forming a well- matched coherent interface observed via high-resolution TEM.
\end{abstract}

\section{Introduction}

Selective reduction and oxidation are fundamental processes of organic synthesis that produce many useful intermediates, like aromatic azo compounds and aldehyde. ${ }^{[1-6]}$ With increasing attention on the energy consumption and environmental issues, photocatalytic processes for the synthesis of fi ne organic chemicals have attracted great interests in recent years. ${ }^{[7-9]}$ However, two main challenges exist in such processes. One is to achieve high effi ciency and selectivity; this is an essential requirement to fi ne chemical production. Another challenge is to utilize visible light, which accounts for about $43 \%$ of the incoming solar energy. Therefore, it is meaningful to develop new photocatalysts with excellent per- formance for both selective reduction of nitroaromatics and oxidation of aromatic alcohols under visible light irradiation.

Gold nanoparticles (Au NPs) can strongly absorb visible light due to local-ized surface plasmon resonance (LSPR) effect. ${ }^{\text {[10-13] }}$ LSPR arises $^{2}$ from the collective oscillation of conduction electrons in the NPs, which resonate with the electromagnetic field of the incident light. ${ }^{[13,14]}{ }^{\text {The }}$ light absorption of these particles depends on their shape and size, ${ }^{[15,16]}$ which means that it is possible to manually design nano structures to utilize the entire solar spectrum by manipulating these properties. In addition, the conduction electrons of Au NPs gain the irradiation energy, becoming excited energetic electrons at the NP surface. Compared with conventional semi-conductor photocatalysts, these energetic electrons on Au NP surface is desirable for activating molecules on the particles for chemical reactions. Furthermore, high reaction efficiency could be attained with $\mathrm{Au}$ NPs photocatalysts as the reaction rate increases with the operating temperature. ${ }^{[17,18]}$ Thus, these NPs could effectively combine thermal energy with photon absorption to drive chemical reactions under visible light irradiation. Recently, our group and other researchers found the photocatalytic activity of Au NPs in these two typical reactions under visible light irradiation. ${ }^{[10-13]}$

$\mathrm{TiO}_{2}$ is a class of useful materials as supports due to its low toxicity and high chemical stability, ${ }^{[19-21]}$ especially $\mathrm{TiO}_{2}$ nanofibers. It has large surface area to volume ratio, easily separated for reuse and particularly suitable for the transmission electron microscopy (TEM) study with the interface structure. ${ }^{[22,23]}$ The ability of the TiO 2 surface to adsorb and activate molecular oxygen, the oxidant in oxidation reactions, profoundly depends on these crystal phases of the $\mathrm{TiO} 2$ supports. ${ }^{[24]}$ Hence, it is rational to hypothesize when different $\mathrm{TiO}_{2}$ crystal phases are used as supports in the Au NP photocatalysts, this ability may contribute to oxidation reactions but affect negatively to reductive reactions. This may also influence the contribution of Au NPs and visible light irradiation to the reaction efficiency. More importantly, visible light excites the conduction electrons of Au NPs directly, which may activate the reactant molecules on Au NPs surface for reactions. Therefore, the contribution of visible light to the reduction should be different from that to the oxidation reactions in which the oxidant comes from or is activated on the $\mathrm{TiO} 2$ surface. Furthermore, it is important to find the preferred orientation and interface information between Au NPs and different phases of $\mathrm{TiO} 2$ nanofiber supports, since solid bonding of Au NPs to the support is essential for the operation life of the photocatalysts and for understanding the contribution of the support to reactant activation in reductive coupling and selective oxidation. This information will motivate the designation of suitable photocatalysts of supported metal NPs for fine chemical synthesis.

This is the peer reviewed version of the following article:Zhao, J., Ke, X., Liu, H., Huang, Y., Chen, C., Bo, A., Sheng, X. and Zhu, H. (2016), Comparing the Contribution of Visible-Light Irradiation, Gold Nanoparticles, and Titania Supports in Photocatalytic Nitroaromatic Coupling and Aromatic Alcohol Oxidation. Part. Part. Syst. Charact., 33: 628-634, which has been published in final form at http://dx.doi.org/10.1002/ ppsc.201600049. This article may be used for non-commercial purposes in accordance With Wiley Terms and Conditions for self-archiving. 


\section{Result and Discussion}

In the present study, visible light was used as light source, and the photocatalytic test was conducted with Au NPs on different phases of TiO 2 supports [TiO2 (B), TiO2(B) core with a shell of anatase- $\mathrm{TiO}_{2}$ (A@B), anatase- $\mathrm{TiO}_{2}(\mathrm{~A})$, and rutile-TiO2 (R)]. The XRD and Raman spectra of the prepared materials are provided in Figure S1 and S2 (Supporting Information). The photocatalytic test results are listed in Table 1 (Table S1 and S2, Supporting Information).

Table 1. The photocatalytic activity of different photocatalysts for reductive coupling of nitrobenzene and oxidation of 4-methoxylbenzyl alcohol under visible-light irradiation.

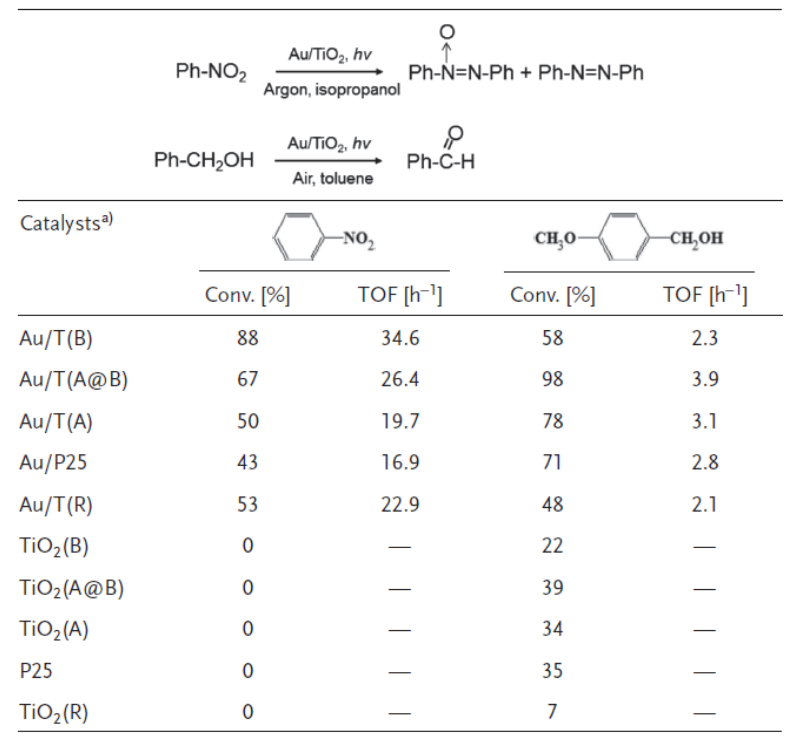

a) Selectivity of corresponding azobenzene and azoxylbenzene $>99 \%$; Selectivity of corresponding aldehydes $>80 \%$. TOF: Turnover frequency is calculated from conversion of the reactant and mole gold content. For the detailed reaction conditions, see Experimental Section.

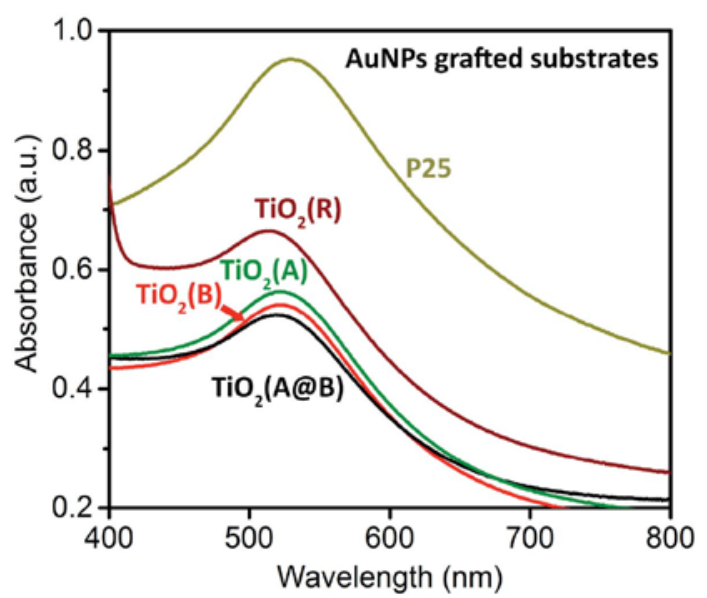

Figure 1. UV-vis diffuse reflectance spectra of Au NPs photocatalysts on different substrates.

The results demonstrate that $\mathrm{Au}$ NPs on $\mathrm{TiO}_{2}$ support are efficient photocatalyst for both reductive coupling of various nitroaromatics and selective oxidation of aromatic alcohols under visible light irradiation. In comparison, no reaction was observed for nitroaromatics reduction in a blank experiment where $\mathrm{TiO}_{2}$ supports are used without Au NPs. For oxidation, Au NPs are also confirmed as the active sites since the conversion measured using only $\mathrm{TiO}_{2}$ as photocatalysts is much lower than that using Au NPs on TiO 2. UV-Vis spectra of these samples in Figure 1 indicate that the supported Au NPs strongly absorb visible light irradiation. There is no adsorption of the light with a wavelength between 420 and $800 \mathrm{~nm}$ by the $\mathrm{TiO}_{2}$ supports used in the present study. The absorption peak in the visible light range observed from the samples of Au NPs on TiO 2 supports is attributed to the LSPR absorption of Au NPs. Evidently, the visible light absorption by Au NPs is a prerequisite for the photocatalytic activity.

The specific surface area of Au NPs was estimated from the size distribution of Au NPs and the detailed calculation information is provided in Figure S3 (Supporting Information). We found that the specific surface area of the supported Au NPs is in accordance to the conversion order over the photocatalysts for reduction of nitroaromatics. The photocatalyst has larger specific surface area of the Au NPs exhibits higher conversion rate. Interestingly, higher intensity of the LSPR absorption does not result in higher conversion rate for the photocatalytic reduction. If we divide the conversion of nitroaromatics by the specific surface area of Au NPs on different supports, the conversion result is similar, as 
shown in Figure 2. The results imply that the Au NPs are the active centers for nitroaromatics reduction. The number of the active centers is primary factor influencing the reduction. In contrast, the performance of the catalysts for selective oxidation of aromatic alcohols does not follow the same trend against the specific surface area of the supported Au NPs. Instead, Au NPs on the supports with anatase surface [TiO2(A), $\mathrm{P} 25, \mathrm{TiO}_{2}(\mathrm{~A} @ \mathrm{~B})$ ] generally exhibit higher conversion than those on a support without the exposed anatase surface [TiO 2(B) and TiO 2(R)] (Figure 2). Anatase surface has a superior ability to adsorb and activate $\mathrm{O}_{2}$ molecules to $\mathrm{TiO}_{2}(\mathrm{~B})$ and rutile phase surfaces, ${ }^{[24]}$ which can facilitate the oxidation reactions.

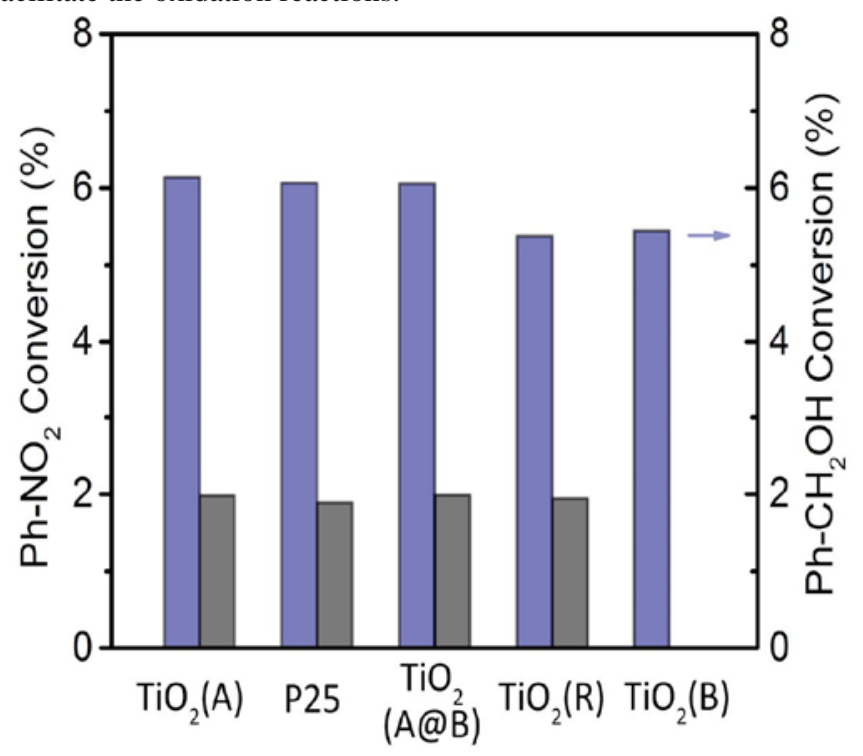

Figure 2. The conversion of nitrobenzene, 4-methoxybenzyl alcohol per surface area of gold nanoparticles on different TiO2 supports. The comparison of other nitroaromatics and aromatic alcohols are provided in Figure S4 (Supporting Information).

A superior property of Au NPs as photocatalysts is that the photocatalytic activity is higher at higher reaction temperature since Au NPs can couple photonic energy and thermal energy at the same time to drive reactions effi ciently, which distinguishes them from semiconductor photocatalysts. ${ }^{[17,18]}$ At a higher temperature, the conducting electrons of Au NPs will redistribute and the population of the electrons at high energy levels increases. Upon light irradiation, these thermally excited electrons can still gain further energy due to LSPR effect, being excited to even higher energy levels. Conduction electrons at higher energy levels have a greater ability to activate the reactant molecules adsorbed on the NP surface to overcome the activation barrier, inducing the reaction. If the catalytic active centers for the reactions were TiO2 rather than $\mathrm{Au} \mathrm{NPs}$, the reaction temperature has no substantial impact on the catalyst performance. Nitrobenzene reductive coupling and selective oxidation of 4-methoxyl benzylalcohol were examined at different reaction temperatures using the photocatalyst of Au NPs on TiO2(B) support. Thermometer was used to monitor the entire photocatalytic process and cooling or heating was used to maintain the temperature variation of the reaction system within $\pm 5{ }^{\circ} \mathrm{C}$. The results are summarized in Figure 3. The reaction rates coupling both the photonic and thermal effect increase with the elevation of reaction temperatures for both reactions. Notably, the reaction rate increased more under high irradiation intensity than that under low irradiation intensity with elevated temperature. Moreover, the reaction rates of nitrobenzene reduction increase faster than that of 4-methoxyl benzylalcohol oxidation, which further indicates that the Au NPs play a much more important role in the reductive coupling than in the selective oxidation.
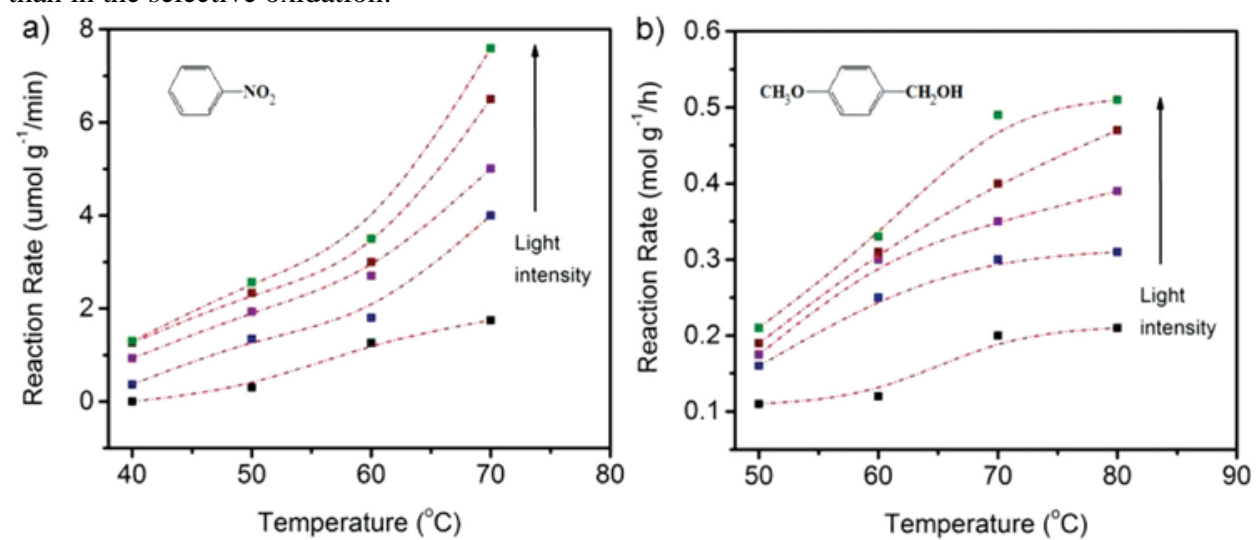

Figure 3. The influence of reaction temperature on the reaction rates of photocatalytic reductive coupling of a) nitrobenzene and b) 4-methoxybenzyl alcohol at various visible-light intensities. Au NPs on $\mathrm{TiO}_{2}(\mathrm{~B})$ was used as the photocatalyst under visible-light irradiation.

Because the photocatalytic activity of the prepared samples varies with temperature, the apparent activation energy can be estimated by using the Arrhenius equation and the kinetics data of photocatalytic reactions conducted under various temperatures. The difference between the activation energies of the light-irradiated reaction and the same reaction carried out in the dark is an indicative of the contribution of 
irradiation toward reducing the apparent activation energy. The reaction kinetics of nitrobenzene and 4-methoxybenzyl alcohol at several temperatures were then studied to derive the apparent activation energies (also called the energy barrier) of the reaction system under irradiation (photocatalytic reaction) and in the dark (thermal catalytic reaction). The calculation procedure of the apparent activation energies is given in Figure S5 and S6 (Supporting Information). For the reductive coupling, the activation energy is $51.1 \mathrm{~kJ} \mathrm{~mol}^{-1}$ under visible light and $75.8 \mathrm{~kJ}^{-1}$ $\mathrm{mol}^{-1}$ in the dark. Therefore, the visible light irradiation on the Au NPs resulted in an activation energy reduction of $24.7 \mathrm{~kJ}$ mol ${ }^{-1}$ for this reaction as shown in Figure 4. For the selective oxidation, the activation energy under visible light is $54.7 \mathrm{~kJ}^{\mathrm{mol}}{ }^{-1}$ and in the dark is $63.4 \mathrm{~kJ}$ $\mathrm{mol}^{-1}$. Thus, the visible light irradiation reduces the activation energy by $8.7 \mathrm{~kJ} \mathrm{~mol}^{-1}$. The fact that light irradiation reduces the activation energy demands implies that the photocatalytic process have a mechanism different from that of the process in the dark.

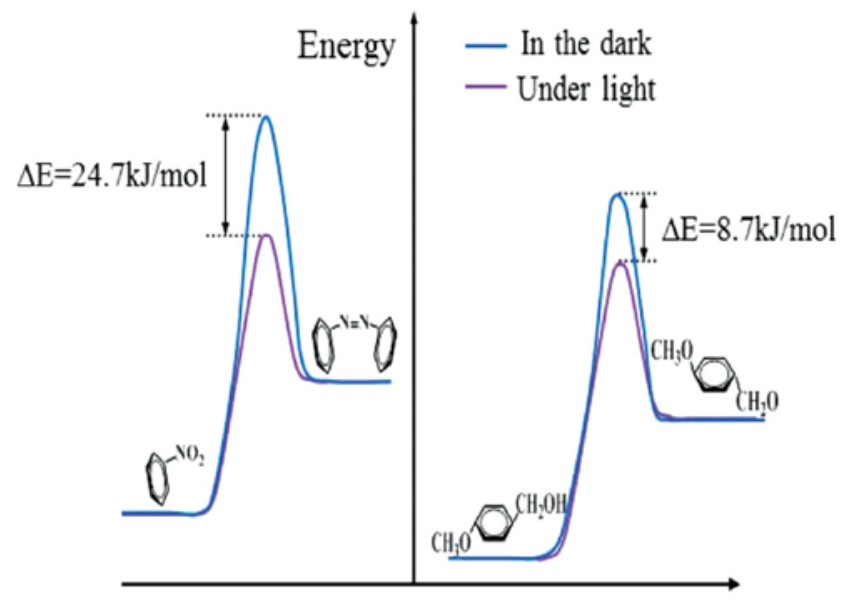

Reaction Pathway

Figure 4. The contribution of visible light to lowering the apparent activation energy of reductive coupling of nitrobenzene (left) is greater than that of selective oxidation of 4-methoxyl benzylalcohol (right).

It is known that the nitrobenzene is activated on the Au NPs under light irradiation, ${ }^{[10]}$ while the $\mathrm{TiO}_{2}$ surface is able to adsorb and activate molecular $\mathrm{O}_{2}$, which is favorable for oxidation. ${ }^{[24]}$ Au NPs have much weaker ability to activate $\mathrm{O}_{2}$ compared with $\mathrm{TiO}_{2}$ surface. ${ }^{[25]} \mathrm{Visible} \mathrm{light}$ irradiation has little contribution to $\mathrm{O}_{2}$ activation. Hence, it is rational that the reduction in activation energy of the oxidation, in which one of the reactant $\mathrm{O}_{2}$ is not activated on the Au NPs, is obviously lower than that of the reductive coupling in which the reactants are activated on the $\mathrm{Au}$ NPs. For the same reason, the infl uence of the irradiation intensity (irradiance) on the reductive coupling is greater than that on the selective oxidation. Much higher photonic efficiency was observed for the reduction than oxidation as shown in Figure 5. There is a positive relationship between the intensity and reaction rate. The results clearly show an almost linear dependence. When the irradiance was increased from 0.15 to $0.29 \mathrm{~W} \mathrm{~cm}^{-2}$ and further to $0.43 \mathrm{~W} \mathrm{~cm}^{-2}$ with other conditions unchanged, the conversion rate of nitrobenzene increased from $40 \%$ to $63 \%$ and $88 \%$, respectively. For the selective oxidation of 4-methoxybenzyl alcohol, when the irradiance was gradually increase from 0.1 to $0.46 \mathrm{~W} \mathrm{~cm}^{-2}$, the contribution of light for conversion rate is from $23 \%$ to $52 \%$ and further down to $59 \%$. The light irradiation influences much more on the reductive coupling with a slope of 171 than on the selective oxidation reaction (slope 103).
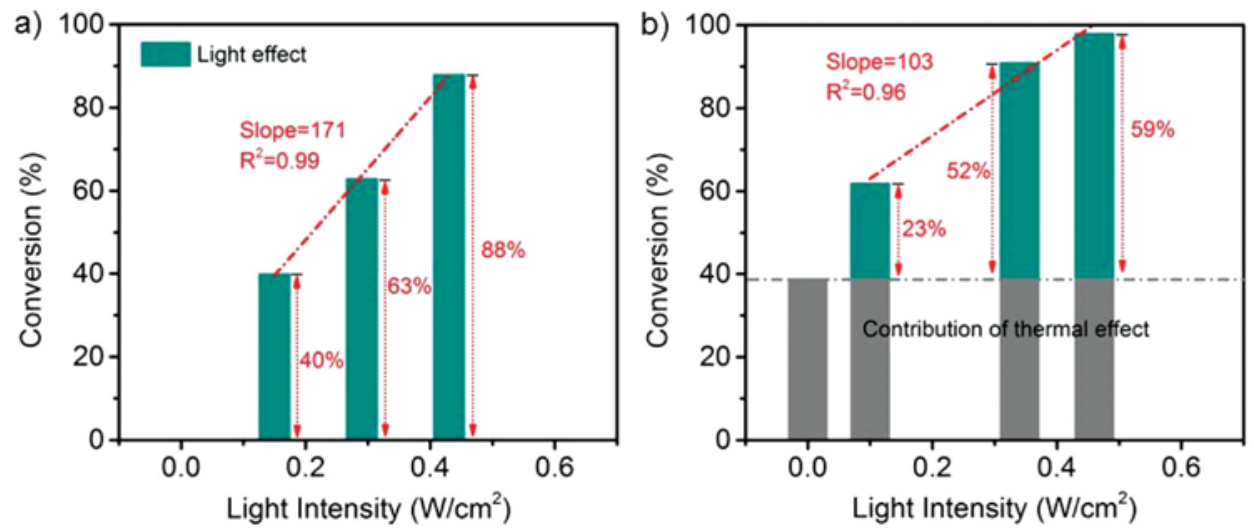

Figure 5. The increase of conversion with visible-light intensity for the reductive coupling of a) nitrobenzene and selective oxidation of b) 4-methoxybenzyl alcohol. The experiment for testing the contribution of thermal effect is conducted in the dark.

The reductive coupling of nitrobenzene and selective oxidation of 4-methyoxybenzyl alcohol were also conducted under sunlight irradiation (using a solar simulator with the same intensity of the visible light we used). The photonic efficiency was $6.8 \%$ for reductive coupling and $1.2 \%$ for the selective oxidation (full details on calculating the photonic efficiency is provided in Supporting Information), which in comparison, is higher than those under visible light (5.0\% for reduction, $0.5 \%$ for oxidation). These results highlight the potential to drive chemical reactions 
with sunlight, an inexhaustible and green energy source.

Interestingly, a general order for the reductive coupling of nitroaromatics was found (more details in Table S1, Supporting Information):

$$
\mathrm{Au} / \mathrm{TiO}_{2}() \mathrm{B}>\mathrm{Au} / \mathrm{TiO}_{2}(\mathrm{~A}+\mathrm{B})>\mathrm{Au} / \mathrm{TiO}_{2}(\mathrm{~A} @ \mathrm{~B})
$$

Structurally, $\mathrm{TiO}_{2}(\mathrm{~A}+\mathrm{B})$ and $\mathrm{TiO} 2(\mathrm{~A} @ \mathrm{~B})$ are the supports of mixed anatase and $\mathrm{TiO}_{2}(\mathrm{~B})$ phases and their phase composition is similar. TEM analysis of these two samples was shown in Figure 6. The $\mathrm{TiO}_{2}(\mathrm{~A} @ \mathrm{~B})$ nanofibers contain a $\mathrm{TiO}_{2}(\mathrm{~B})$ core which is covered by anatase nanocrystals, ${ }^{[26]}$ while the exposed external surface of $\mathrm{TiO}_{2}(\mathrm{~A}+\mathrm{B})$ nanofibers are both $\mathrm{TiO}_{2}(\mathrm{~B})$ surface (major) and anatase (minor). ${ }^{[23]}$ Hence, it appears the larger the fraction of the external surface of the $\mathrm{TiO}_{2}$ support is anatase phase, the lower the conversion of the reductive coupling achieved by the catalyst of the Au NPs supported on such a support. For instance, the conversions for Au NPs on TiOz (A+B) support (B, 88\% and anatase 12\%) is $80 \%$ (Table 1), while the experimental conversion of Au/T(A@B) is much lower, 67\%, as most of the external surface of $\mathrm{TiO}_{2}(\mathrm{~A} @ \mathrm{~B})$ support is anatase phase. Compared with $\mathrm{TiO}$ 2(B) and rutile, the anatase surface has higher ability to activate oxygen, which possibly affects the reductive coupling negatively as shown in Table 1. These results indicate that the properties of the external surface of support have important influence on the photocatalysts' performance, and one may optimize the performance by modifying the surface of the support. For instance, if we modify the $\mathrm{TiO}_{2}$ surface to inhibit the oxygen adsorption, higher performance should be observed. Then, $\mathrm{TiO}$ (B) covered by $\mathrm{N}$ species [noted as $\mathrm{TiO}_{2}(\mathrm{~B})-\mathrm{N}$ ] was prepared by calcining $\mathrm{H}$-titanate nanofibers at $550{ }^{\circ} \mathrm{C}$ in ammonia gas flow for $3 \mathrm{~h} .{ }^{[27]}$ Indeed, the $\mathrm{Au}$ NPs supported on $\mathrm{TiO}_{2}(\mathrm{~B})-\mathrm{N}$ [noted as $\mathrm{Au} / \mathrm{T}(\mathrm{B})-\mathrm{N}$ ] exhibits superior performance to other photocatalysts, with a nearly $100 \%$ of nitrobenzene conversion (as shown in Table S1, Supporting Information).

a)

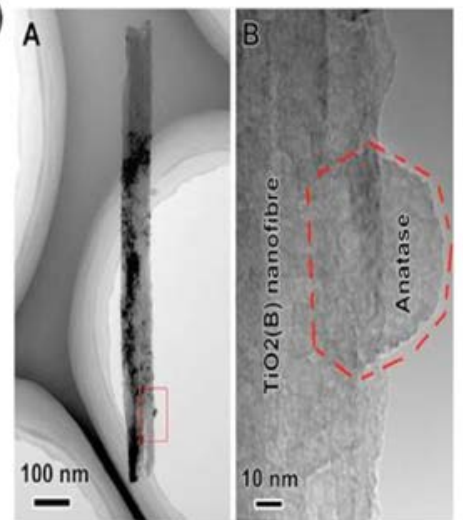

b) $A$

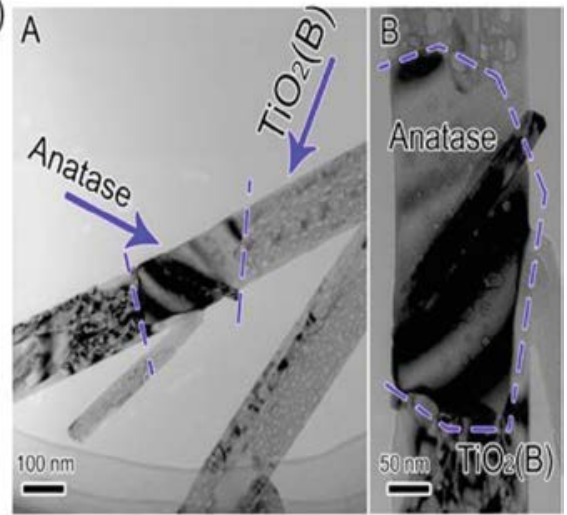

Figure 6. a) TEM of $\mathrm{TiO}_{2}(\mathrm{~B})$ core with a shell of anatase- $\mathrm{TiO}_{2}(\mathrm{~A} @ \mathrm{~B})$. b) TEM of mixed anatase and $\mathrm{TiO}_{2}(\mathrm{~B})$ nanofiber-TiO2(A+B). The exposed external surface consist of both $\mathrm{TiO}_{2}(\mathrm{~B})$ and anatase.

It is also noted that anatase surface of the $\mathrm{TiO}_{2}$ support the photocatalyst of Au NPs on the support with anatase phase at the external surface, such as $\mathrm{TiO}_{2}(\mathrm{~A}), \mathrm{P} 25$, and $\mathrm{TiO}_{2}$ (A@B) exhibit better catalytic conversion for selective oxidation of aromatic alcohols under visible light irradiation than those of $\mathrm{Au}$ NPs on rutile and $\mathrm{TiO}_{2}(\mathrm{~B})$ supports. For the selective oxidation, a key step is to adsorb and activate the oxidant, molecular $\mathrm{O}_{2}$. According to the results of the selective oxidation, the adsorption and activation of oxygen molecule should take place on the surface of the $\mathrm{TiO}_{2}$ support the photocatalysts. Therefore, the $\mathrm{TiO}$ 2 support can contribute positively to the photocatalyst performance for the selective oxidation. This also explains the observation that the contribution from the supported Au NPs in the oxidation is less than that in the reductive coupling (Figure 4).

The interfaces between $\mathrm{Au}$ NPs and $\mathrm{TiO}_{2}$ nanofiber supports are of great importance for the properties of the photocatalysts, which were determined by using high resolution TEM (HRTEM). As shown in Figure 7, the planes between three TiO2 phases and Au NPs are well matched via the crystal planes that have the similar basal spacing. Hence, the NPs and fibers can interlock tightly at the atomic level to form stable structure. For $\mathrm{TiO}_{2}(\mathrm{R})$, the misfit between the two close-packed planes is less that $5 \%$ and the good parallel matching is [111] $/ /[110]_{\mathrm{r}}$ (Figure 7a), which is also observed by Haruta. ${ }^{[28-30]}$ As also shown in panel A of Figure 7c, Au NPs are easier to deposit on the nanofibers with larger quantity of defects, such as $\mathrm{TiO}_{2}(\mathrm{~B})$ nanofibers. The preference for adhesion of Au NPs on oxygen defects has already been confirmed. ${ }^{[31]}$ From Figure 7b, it can be seen that nanocrystals anatase has an perfect exposure (100)a plane as supporting surface of Au NPs. Therefore, with consideration of perfect exposure plane (100)a, the deposition density of Au NPs on anatase should be less than that on TiO 2(B). The high density of Au NPs or small inter-particle distance will result in coupled SPR absorption and the surface enhancement for Raman intensity. ${ }^{[32-34]}$ This may the reason the higher performance of $\mathrm{Au} \mathrm{NPs}$ on $\mathrm{TiO}_{2}(\mathrm{~B})$ for the reductive coupling of nitroaromatics. 
a)
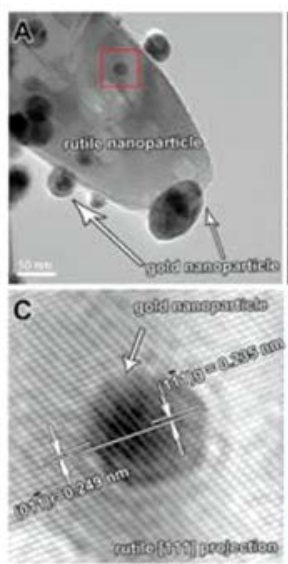
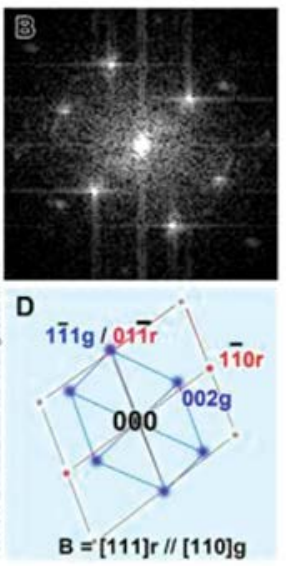

b)

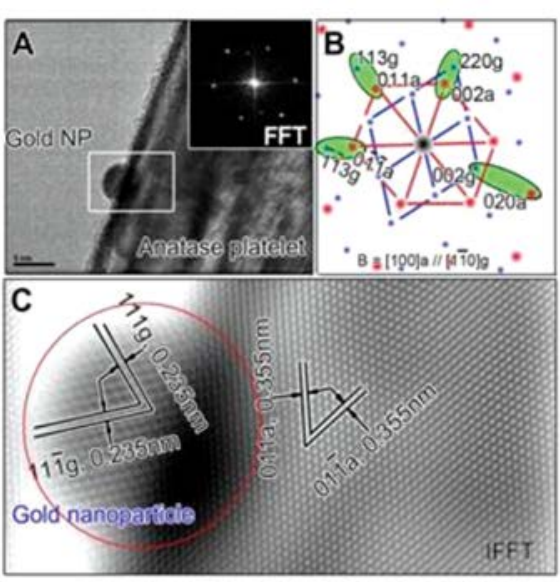

c)

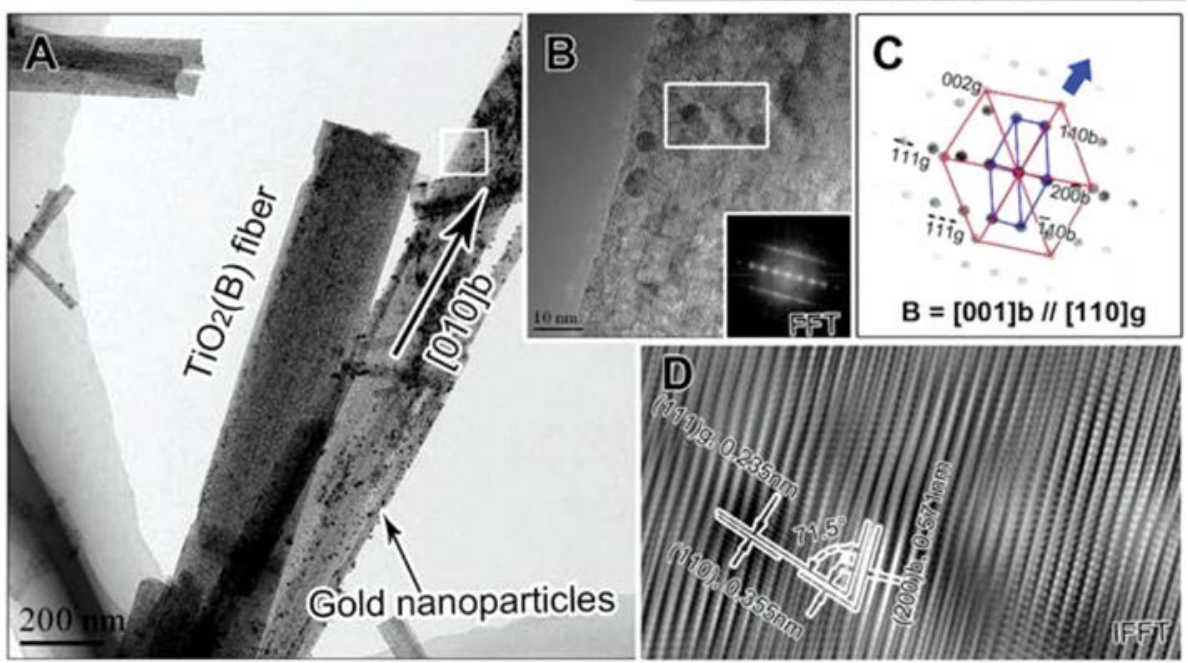

Figure 7. TEM analysis of gold nanoparticles supported on a) $\mathrm{TiO}_{2}(\mathrm{R})$, b) $\mathrm{TiO}_{2}(\mathrm{~A})$ and c) $\mathrm{TiO}_{2}(\mathrm{~B})$ nanofibers. g-gold nanoparticles, a-anatase, r-rutile.

\section{Conclusion}

In summary, TiO 2 nanofiber-supported Au NPs could effectively couple the photonic energy from visible light and thermal energy to drive reductive coupling of nitroaromatics and selective oxidation of aromatic alcohols. We have also shown that the performance of these photocatlysts for the reduction depends on the properties of Au NPs, the same order as the particle size and surface area of Au NPs. The contributions of visible light irradiation, $\mathrm{Au} \mathrm{NPs}$ and $\mathrm{TiO}_{2}$ supports to catalytic performance for two typical reactions are different. The reductive coupling of nitroaromatics prefer $\mathrm{TiO}_{2}(\mathrm{~B})$ as support, which is different from that $\mathrm{TiO}_{2}(\mathrm{~A})$ for oxidation of aromatic alcohols. It is also found that these synthetic reactions can be efficiently driven by sunlight at ambient temperatures. Moreover, preferred orientation and planar matching between $\mathrm{Au}$ NPs and $\mathrm{TiO}_{2}$ nanofibers were observed. These findings provide useful information on designation of efficient catalysts in supported metal NPs for fine chemical synthesis.

\section{Experimental Section}

Synthesis of Different Phases of $\mathrm{TiO}_{2}$ Supports: Supports of different $\mathrm{TiO}_{2}$ phases were prepared through various post treatments of hydrogen titanate fibers (except P25 purchased from Chem Supply). The sodium titanate fibers were obtained by a hydrothermal treatment of anatase particles $(6 \mathrm{~g})$ with $80 \mathrm{~mL}$ of $10 \mathrm{M}$ $\mathrm{NaOH}$ solution, and the subsequent ion exchange with $0.1 \mathrm{~m} \mathrm{HCl}$ solution yielded hydrogen titanate (H-titanate) fibers. TiO 2 (B) was obtained by calcining the hydrogen titanate fibers at $723 \mathrm{~K}$ for $3 \mathrm{~h}$. TiO 2 (B)-anatase core-shell nanofibers were prepared by a two-step treatment. First, outer anatase shell was formed through hydrothermal reaction of $\mathrm{H}$-titanate with dilute $(0.05 \mathrm{~m}) \mathrm{HNO}_{3}$ solution for $18 \mathrm{~h}$, as described in our previous study. Then, these samples were calcined at $723 \mathrm{~K}$ for $3 \mathrm{~h}$ to convert the $\mathrm{H}_{2} \mathrm{Ti}_{3} \mathrm{O}_{7}$ phase to $\mathrm{TiO}_{2}(\mathrm{~B})$ while the outer anatase shell remained unchanged. The prepared sample was denoted as TiO2 $(\mathrm{A} @ \mathrm{~B})$. By prolonging the hydrothermal reaction of $\mathrm{H}$-titanate with dilute $\mathrm{HNO}_{3}$ solution to $62 \mathrm{~h}$, we obtained pure anatase support [TiO2(A)]. For comparison, pure rutile support $\left[\mathrm{TiO}_{2}(\mathrm{R})\right]$ was prepared by dispersing $\mathrm{H}$-titanate into concentrated (2.65 $\left.\mathrm{M}\right) \mathrm{HNO}$ z solution and then hydrothermal reaction at $353 \mathrm{~K}$ for $72 \mathrm{~h}$. Finally, $\mathrm{TiO}_{2}\left(\mathrm{~A} @ \mathrm{~B}\right.$ ), $\mathrm{TiO}_{2}(\mathrm{~A})$, and $\mathrm{TiO}_{2}(\mathrm{R})$ were calcined at $723 \mathrm{~K}$ for $3 \mathrm{~h}$ to keep the temperature of calcinations the same as $\mathrm{TiO}_{2}(\mathrm{~B})$.

Au NPs Loading: Reduction methods were used to prepare the Au NPs supported on $\mathrm{TiO}_{2}$ supports of different phases. Typically, $2.5 \mathrm{~g}$ of support powder was dispersed into $100 \mathrm{~mL}$ of a designed concentration of $\mathrm{HAuCl}_{4}$ solution. $20 \mathrm{~mL}$ of $0.53 \mathrm{~m}$ lysine was then added under magnetic stirring and the suspension was stirred for $30 \mathrm{~min}$. To this suspension, $10 \mathrm{~mL}$ of $0.35 \mathrm{~m} \mathrm{NaBH} 4$ solution was added gradually. Then, $10 \mathrm{~mL}$ of $0.3 \mathrm{~m}$ hydrochloric acid was added and the mixture was aged for 24 h. Finally, the solid was separated, washed with deionized water and ethanol, and dried at 343 K. The Au NPs on TiO2 (B), TiO2(A@B), $\mathrm{TiO}_{2}(\mathrm{~A}), \mathrm{TiO}_{2}(\mathrm{R})$, and $\mathrm{P} 25$ are, respectively, denoted as $\mathrm{Au} / \mathrm{T}(\mathrm{B}), \mathrm{Au} / \mathrm{T}(\mathrm{A} @ \mathrm{~B}), \mathrm{Au} / \mathrm{T}(\mathrm{A}), \mathrm{Au} / \mathrm{T}(\mathrm{R})$, and Au/P25.

Characterization: XRD patterns of the samples were recorded on a Philips PANalytical X'Pert PRO diffractometer using Cu Ka radiation ( $\lambda=1.5418 \AA)$ operating at $40 \mathrm{kV}$ and $40 \mathrm{~mA}$ with a fixed slit. To investigate the light absorption and emission behavior of the samples as well as their energy bandgap, the diffuse reflectance UV-Vis (DR-UV-vis) spectra of the samples were recorded on a Varian Cary 5000 spectrometer. The nitrogen sorption isotherms were measured by volumetric method on an automatic adsorption instrument (Micromeritics, Tristar 3000) at liquid nitrogen temperature (77 K). Specific surface area was calculated by the Brunauer-Emmett-Teller (BET) method from the data in a $P / P_{0}$ range between 0.05 and 0.2 . The gold content of the prepared catalysts was determined by energy disperse X-ray (EDX) spectrum technology using the attachment to a FEI Quanta 200 Environmental SEM. Transmission electron 
microscopy (TEM) study of the photocatalysts was carried out on Philips CM200 TEM with an accelerating voltage of $200 \mathrm{kV}$.

Photocatalytic Activity Test-Selective Reduction of Nitroaromatics: Typically, 0.1 g synthesized catalyst was dispersed in $30 \mathrm{~mL}$ isopropanol (IPA). 3 mmol nitroaromatics and $3 \mathrm{~mL} 0.1 \mathrm{~m} \mathrm{KOH} / \mathrm{IPA}$ were then added. The flask was then filled with argon for 1 min to eliminate the air. The suspension was illuminated with a $500 \mathrm{~W}$ Halogen lamp (as the light source) and the light intensity was measured to be $0.43 \mathrm{~W} \mathrm{~cm}^{-2}$. Fans were used to keep the reaction temperature at $45 \pm 2{ }^{\circ} \mathrm{C}$. At given irradiation time intervals, $1 \mathrm{~mL}$ aliquots were collected and filtered through a Millipore filter (pore size $0.45 \mu \mathrm{m}$ ) to remove the catalyst particulates. The flask was filled with argon after collecting samples every time. The filtrates were analyzed in a gas chromatography (GC, HP6890 Prometheus) to measure concentration change of nitroaromatics and products. GC-MS was used to analyze the products.

Photocatalytic Activity Test-Selective Oxidation of Aromatic Alcohols: $0.2 \mathrm{~mL}$ aromatic alcohol was dissolved into $10 \mathrm{~mL}$ toluene and $0.1 \mathrm{~g}$ photocatalyst was added. The flask was then filled with oxygen for $1 \mathrm{~min}$ to eliminate the air. After that, the mixture was illuminated with a $500 \mathrm{~W}$ Halogen lamp (0.46 W $\mathrm{cm}^{-2}$ ) for $24 \mathrm{~h}$. At given irradiation time intervals, liquid specimens were collected and tested with the same procedure described above.

\section{Supporting Information}

Supporting Information is available from the Wiley Online Library or from the author.

\section{Acknowledgements}

The authors also gratefully acknowledge financial support from the Australia Research Council (ARC DP110104990).

Received: February 22, 2016 Revised: March 30, 2016

[1] R. K. Grasselli, Top. Catal. 2002, 21, 79 .

[2] C. Zhang, N. Jiao, Angew. Chem. Int. Ed. 2010, 49, 6174.

[3] R. G. Anderson, G. Nickless, Analyst 1967, 92, 207.

[4] G. J. Brink, I. W. C. E. Arends, R. A. Sheldon, Science 2000, 287, 1636.

[5] S. Higashimoto, N. Kitao, N. Yoshida, T. Sakura, M. Azuma, H. Ohue, Y. Sakata, J. Catal. 2009, 266, 279.

[6] S. Higashimoto, N. Suetsugu, M. Azuma, H. Ohue, Y. Sa-kata, J. Catal. 2010, 274, 76.

[7] G. Palmisano, V. Augugliaro, M. Pagliaro, L. Palmisano, Chem. Commun. 2007, 33, 3425.

[8] G. Palmisano, E. G. López, G. Marcí, V. Loddo, S. Yurdakal, V. Augugliaro, L. Palmisano, Chem. Commun. 2010, 46, 7074.

[9] Y. Shiraishi, T. J. Hirai, Photochem. Photobiol. C: Photochem. Rev. 2008, 9, 157.

[10] H. Y. Zhu, X. B. Ke, X. Z. Yang, S. Sarina, H. W. Liu, Angew. Chem. Int. Ed. 2010, 49, 9657.

[11] S. Eustis, M. A. El-Sayed, Chem. Soc. Rev. 2006, 35, 209.

[12] S. Link, M. A. El-Sayed, Int. Rev. Phys. Chem. 2000, 19, 409.

[13] L. M. Liz-Marzán, Langmuir 2006, 22, 32.

[14] V. Myroshnychenko, J. R. Fernández, I. P. Santos, A. M. Funston, C. Novo, P. Mulvaney, L. M. Liz-Marzán, F. J. G. Abajo, Chem. Soc. Rev. 2008, 37, 1792.

[15] K. L. Kelly, E. Coronado, L. L. Zhao, G. C. Schatz, J. Phys. Chem. B 2003, 107, 668.

[16] K. Yamada, K. Miyajima, F. Mafun, J. Phys. Chem. C 2007, 111, 11246.

[17] S. Linic, P. Christopher, D. B. Ingram, Nat. Mater. 2011, 10, 911.

[18] P. Christopher, H. L. Xin, A. Marimuthu, S. Linic, Nat. Mater. 2012, 11, 1044.

[19] A. Fujishima, K. Hongda, Nature 1972, 238, 37.

[20] A. L. Linsebigler, G. Q. Lu, J. T. Yates, Chem. Rev. 1995, 95, 735.

[21] T. L. Thompson, J. T. Yates, Chem. Rev. 2006, 106, 4428.

[22] H. Y. Zhu, Y. Lan, X. P. Gao, S. P. Ringer, Z. F. Zheng, D. Y. Song, J. C. Zhao, J. Am. Chem. Soc. 2005, 127, 6730.

[23] Z. F. Zheng, H. W. Liu, J. P. Ye, J. C. Zhao, E. R. Waclawik, H. Y. Zhu, J. Mol. Catal. A: Chem. 2010, 316, 75.

[24] Z. F. Zheng, J. Teo, X. Chen, H. W. Liu, Y. Yuan, E. R. Waclawik, Z. Y. Zhong, H. Y. Zhu, Chem. Eur. J. 2010, 16, 1202.

[25] M. M. Schubert, S. Hackenberg, A. C. Veen, M. Muhler, V. Plzak, R. J. Behm, J. Catal. 2001, 197, 113.

[26] D. J. Yang, H. W. Liu, Z. F. Zheng, Y. Yuan, J. C. Zhao, E. R. Waclawik, X. B. Ke, H. Y. Zhu, J. Am. Chem. Soc. 2009, $131,17885$.

[27] Z. F. Zheng, J. Zhao, Y. Yuan, H. W. Liu, D. J. Yang, S. Sarina, H. J. Zhang, E. R. Waclawika, H. Y. Zhu. Chem. Eur. J. $2013,19,5731$.

[28] T. Akita, K. Tanaka, S. Tsubota, M. Haruta, J. Electron Microsc. 2000, 49, 657.

[29] T. Akita, P. Lu, S. Ichikawa, K. Tanaka, M. Haruta, Surf. Interface Anal. 2001, 31, 73.

[30] D. Tsukamoto, Y. Shiraishi, Y. Sugano, S. Ichikawa, S. Tanaka, T. Hirai, J. Am. Chem. Soc. 2012, 14, 6309.

[31] N. Lopez, J. K. Nørskov, T. V. W. Janssens, A. Carlsson, A. Puig-Molina, B. S. Clausen, J. D. Grunwaldt, J. Catal. 2004, $225,86$.

[32] H. B. Chu, J. Y. Wang, L. Ding, D. N. Yuan, Y. Zhang, J. Liu, Y. Li, J. Am. Chem. Soc. 2009, 131, 14310.

[33] P. J. Schuck, D. P. Fromm, A. Sundaramurthy, G. S. Kino, W. E. Moerner, Phys. Rev. Lett. 2005, 94, 17402.

[34] H. X. Xu, J. Aizpurua, M. Kall, P. Apell, Phys. Rev. E 2000, 62, 4318. 